\title{
A Gemini-Type Supramolecular Amphiphile Based on a Water-Soluble Pillar[5]arene and an Azastilbene Guest and Its Application in Stimuli-Responsive Self-Assemblies $\dagger$
}

\begin{abstract}
Xiaoqing Lv, ${ }^{\dagger,}$ Danyu Xia, ${ }^{* \dagger}$ Ying Zuo,${ }^{\dagger}$ Xiaoqin Wu, ${ }^{\dagger}$ Xuehong Wei**,* and Pi Wang*§
${ }^{\dagger}$ Scientific Instrument Center, Shanxi University, Taiyuan 030006, P. R. China

${ }^{*}$ School of Chemistry and Chemical Engineering, Shanxi University, Taiyuan 030006, P. R. China

${ }^{\S}$ Ministry of Education Key Laboratory of Interface Science and Engineering in Advanced Materials, Research Center of Advanced Materials Science and Technology, Taiyuan University of Technology, Taiyuan 030024, P.R. China
\end{abstract}

\section{Electronic Supplementary Information (9 pages)}

1. Materials and Methods $\quad S 2$

2. X-ray crystal data of $\boldsymbol{G 1} \quad S 2$

3. Partial 2D NOESY spectrum of an equimolar solution of WP5 and G1 S3

4. Isothermal titration calorimetry (ITC) experiment of WP5 and G1 S4

5. Partial 2D NOESY spectrum of WP5 and G2 S5

6. ITC experiment of WP5 and $\mathbf{G 2} \quad S 6$

7. High-resolution mass spectrum of WP5 $3 \mathbf{3 G 2} \quad S 7$

8. Critical aggregation concentration $(C A C)$ determination of $\mathbf{G} \mathbf{2}, \mathbf{G} \mathbf{2}^{\prime}$ and $\begin{array}{ll}W P 5 & 3 G 2\end{array}$

9. DFT-optimized structure of $\mathbf{G} \mathbf{2}$ by Gaussian computer program S8

10. The theoretical extended length of $\mathbf{W P 5} \supset 3 \mathbf{G 2} S 8$

References $\quad S 9$ 


\section{Materials and methods}

All reagents were commercially available and used as supplied without further purification. Compounds $\mathbf{W P 5}^{\mathrm{S} 1}, \mathbf{G 1}^{\mathrm{S} 2}$ and $\mathbf{G} 2^{\mathrm{S} 3}$ were prepared according to published procedures. NMR spectra were recorded with a Bruker Avance DMX 600 spectrophotometer. Isothermal titration calorimetric (ITC) measurements were performed on a MicroCal iTC200 instrument. High-resolution mass spectrometry experiments were performed with a Waters UPLC H-Class QDA instrument.The determination of the critical aggregation concentration (CAC) values was carried out on a FE38-Standard Bench Instrument. Transmission electron microscopy investigations were carried out on a JEM-2100 or a JEM-1200EX instrument. Atomic force microscopy experiments were performed by a Bruker Multi-Mode 8.0 instrument. The data of the single crystal structure were collected on a Bruker APEX-II CCD X-ray diffractometer and processed using the Bruker SAINT v8.37A. The crystal structures were solved by SHELXT $^{\text {S4 }}$ and refined by SHELXL. ${ }^{\text {S5 }}$ Density functional theory (DFT) by the Gaussian 09 program were carried out at the B3LYP/6-31+G(d). ${ }^{\mathrm{S} 6}$ The PCM was also employed in the calculations, and the solvent is water. The optimized structure G2 is shown in Fig. S4. The extended length of G2 is calculated to be $2.385 \mathrm{~nm}$.

\section{X-ray crystal data of $\mathbf{G} \mathbf{1}$}

Crystal data of G1: colorless, $\mathrm{C}_{39} \mathrm{H}_{42} \mathrm{O}_{18}, F W 324.16$, monoclinic, space group $P 2{ }_{1} / c, a=11.1255(9)$, $b=20.0207(16), c=12.9989(10) \AA, \alpha=90.00^{\circ}, \beta=111.552(2)^{\circ}, \gamma=90.00^{\circ}, V=2692.9(4) \AA^{3}, Z=4, D_{\mathrm{c}}$ $=1.634 \mathrm{~g} \mathrm{~cm}^{-3}, T=200 \mathrm{~K}, \mu=2.358 \mathrm{~mm}^{-1}, 19531$ measured reflections, 4711 independent reflections, 300 parameters, 0 restraints, $F(000)=1292.0, R_{1}=0.0276, w R_{2}=0.0632$ (all data), $R_{1}=0.0246, w R_{2}=$ $0.0618[I>2 \sigma(I)]$, max. residual density $0.729 \mathrm{e} \bullet \AA^{-3}$, and goodness-of-fit $\left(F^{2}\right)=1.050$. CCDC-1875918. 
3. Partial 2D NOESY NMR spectrum of an equimolar solution of WP5 and G1

2D NOESY experiment was employed to study the relative positions of the components in complex WP5 $\supset$ G1. NOE correlation signals were observed between proton $\mathrm{H}_{\mathrm{b}}$ of G1 and protons $\mathrm{H}_{3}$ of WP5 (Fig. $\mathrm{S} 1$, A), between proton $\mathrm{H}_{\mathrm{c}}, \mathrm{H}_{\mathrm{d}}, \mathrm{H}_{\mathrm{f}}$ of $\mathbf{G}$ and protons $\mathrm{H}_{2}$ and $\mathrm{H}_{3}$ of WP5 (Fig. S1, B and C), indicating that G1 threaded into the cavity of WP5.

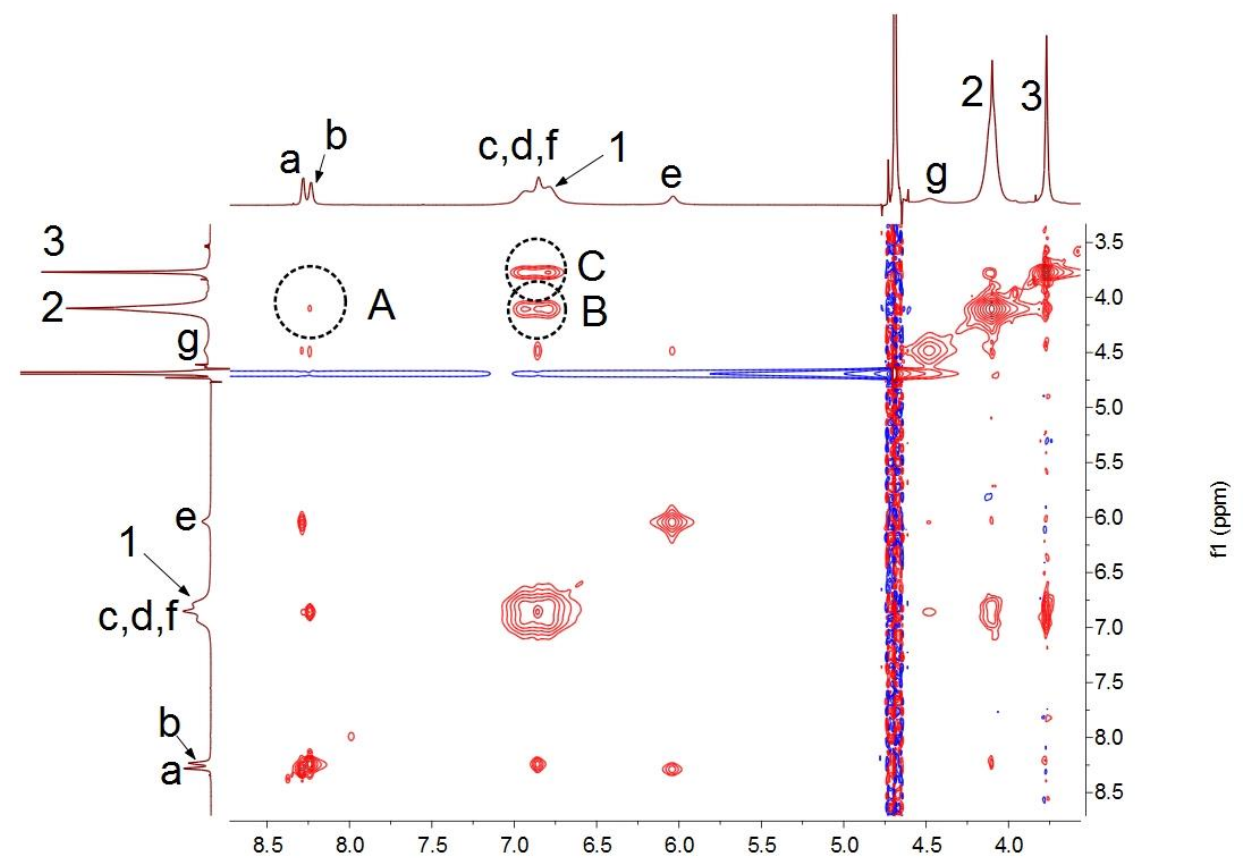

Figure S1 Partial 2D NOESY spectra $\left(\mathrm{D}_{2} \mathrm{O}, 293 \mathrm{~K}, 600 \mathrm{MHz}\right)$ of equimolar mixture WP5 and G1 (12.5 $\mathrm{mM})$. 


\section{Isothermal titration calorimetry (ITC) experiment}

ITC is a useful tool to study the association constant $\left(K_{\mathrm{a}}\right)$, stoichiometry of host-guest complexes and thermodynamic parameters (enthalpy change $\Delta H$ and entropy change $\Delta S$ ). As shown in Fig. S2, the enthalpy and entropy changes of WP5 $\supset \mathbf{G 1}$ were obtained $(\Delta H<0 ; T \Delta S>0 ;|\Delta H|>|T \Delta S|)$, indicating that this complexation was driven by enthalpy changes with entropy change assistance.

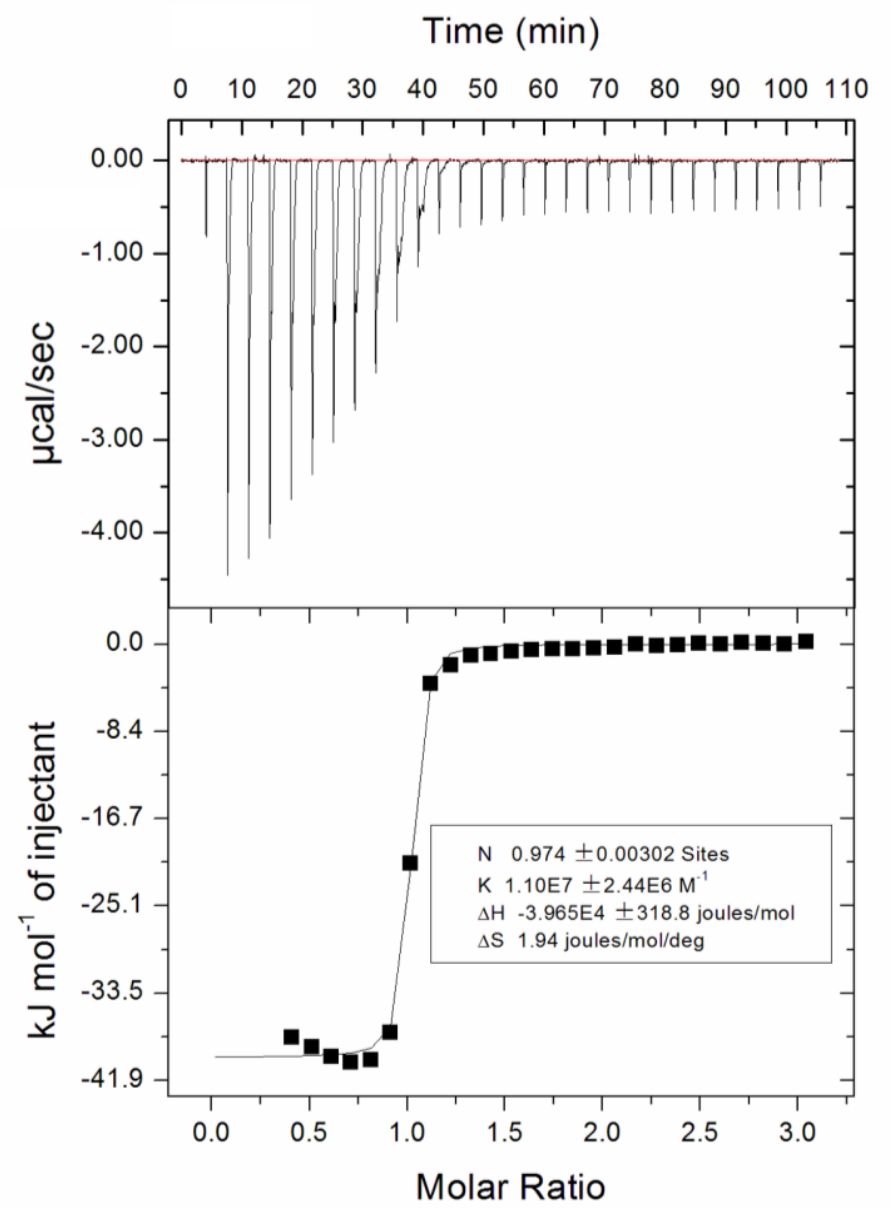

Figure S2 Microcalorimetric titration of WP5 with G1 in water at 298 K. (Top) Raw ITC data for 30 sequential injections (1.0 $\mu \mathrm{L}$ per injection) of a G1 solution $\left(2.00 \mathrm{Mm}\right.$ in $\mathrm{H}_{2} \mathrm{O}$ ) into a WP5 solution (0.100 $\mathrm{mM}$ in $\mathrm{H}_{2} \mathrm{O}$ ). (Bottom) Net reaction heat obtained from the integration of the calorimetric traces. 
5. Partial 2D NOESY spectrum of an equimolar solution of WP5 and $\boldsymbol{G 2}$

2D NOESY experiment was employed to study the relative positions of the components in complex based on WP5 and G2. NOE correlation signals were observed between proton $\mathrm{H}_{\mathrm{i}}, \mathrm{H}_{\mathrm{h}}$ and $\mathrm{H}_{\mathrm{g}}$ of $\mathbf{G} 2$ and protons $\mathrm{H}_{1}$ of WP5 (Fig. S4, A, B and C), between proton $\mathrm{H}_{\mathrm{i}}$ and $\mathrm{H}_{\mathrm{h}}$ of $\mathbf{G} 2$ and protons $\mathrm{H}_{2}$ of WP5 (Fig. S4, D and E), between proton $\mathrm{H}_{\mathrm{i}}$ of $\mathbf{G} 2$ and protons $\mathrm{H}_{3}$ of WP5 (Fig. S4, F), indicating that the pyridium and alkyl part of G2 threaded into the cavity of WP5.

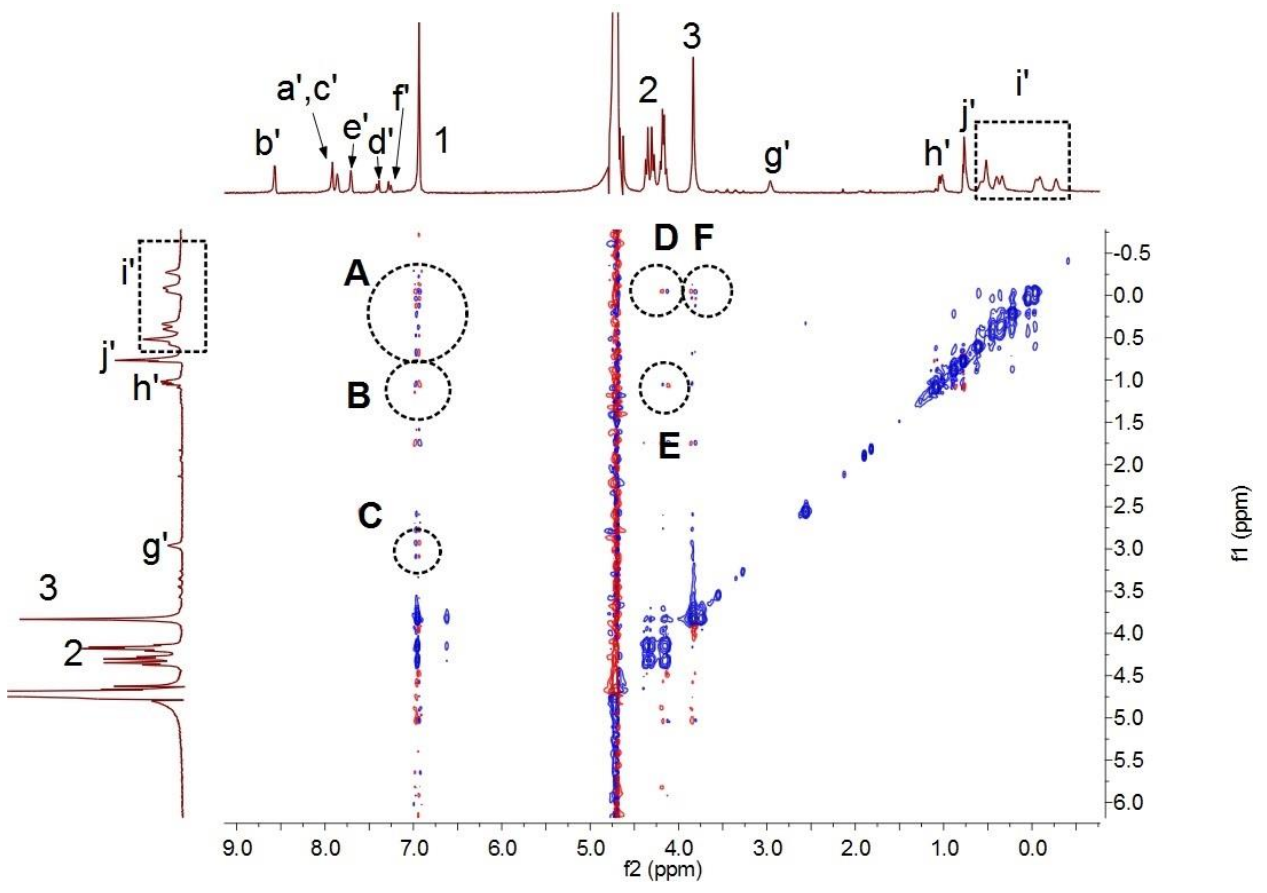

Figure S3 Partial 2D NOESY spectra $\left(\mathrm{D}_{2} \mathrm{O}, 293 \mathrm{~K}, 600 \mathrm{MHz}\right)$ of the mixture of WP5 (3.00 mM) and G2 (9.00 mM). 
6. Isothermal titration calorimetry (ITC) experiment of WP5 and $\mathbf{G 2}$

As shown in Fig. S5, the enthalpy and entropy changes of WP5 and G2 complexes were obtained $(\Delta H$ $<0 ; T \Delta S>0 ;|\Delta H|>|T \Delta S|)$, indicating that this complexation was driven by enthalpy changes with entropy change assistance.

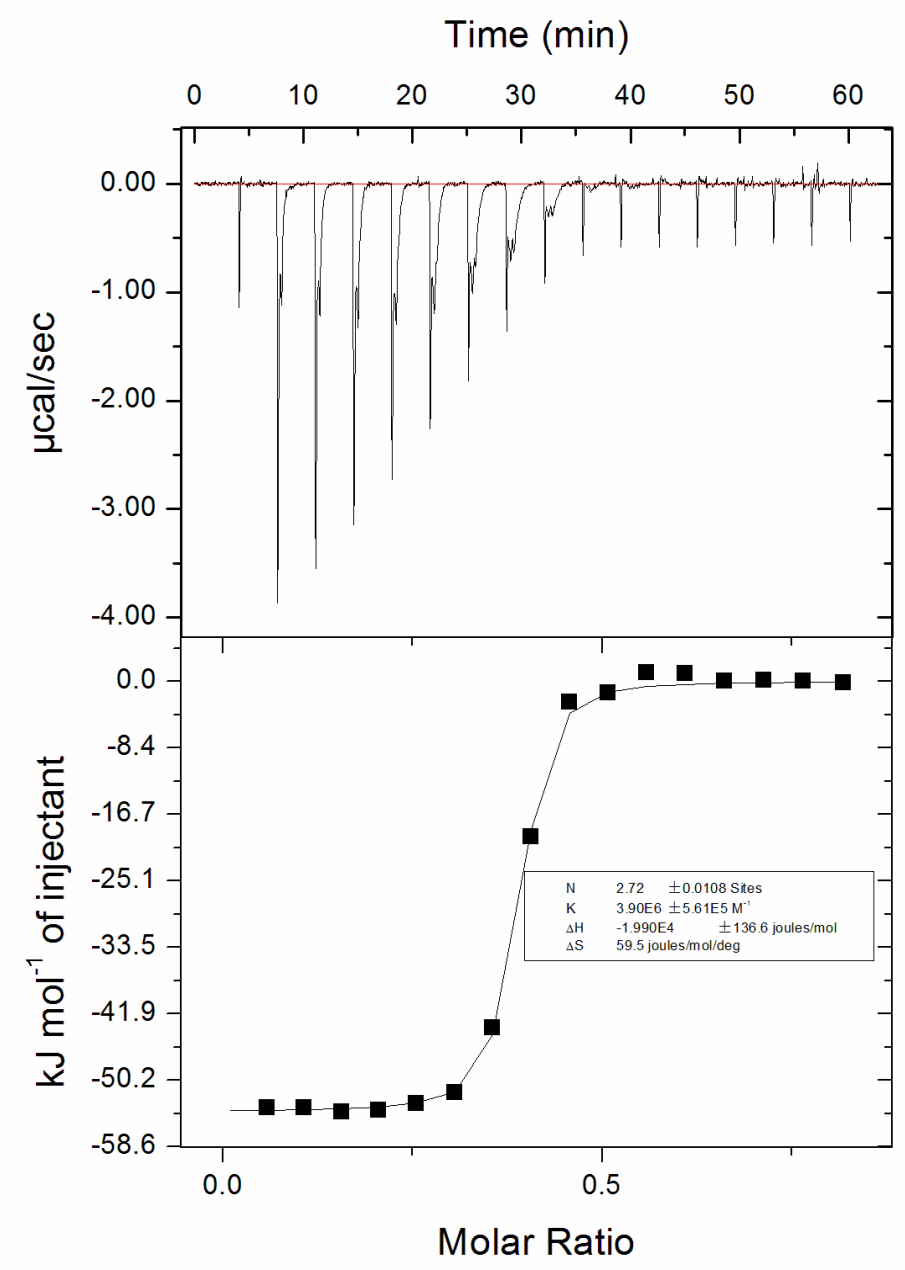

Figure S4 Microcalorimetric titration of WP5 with G2 in water at 298 K. (Top) Raw ITC data for 17 sequential injections $\left(2.0 \mu \mathrm{L}\right.$ per injection) of a WP5 solution $\left(1.00 \mathrm{mM}\right.$ in $\left.\mathrm{H}_{2} \mathrm{O}\right)$ into a $\mathbf{G 2}$ solution $\left(0.100 \mathrm{mM}\right.$ in $\left.\mathrm{H}_{2} \mathrm{O}\right)$. (Bottom) Net reaction heat obtained from the integration of the calorimetric traces. The data was processed by changing to have ligands in Cell. 
7. High-resolution mass spectrum of WP5د3G2

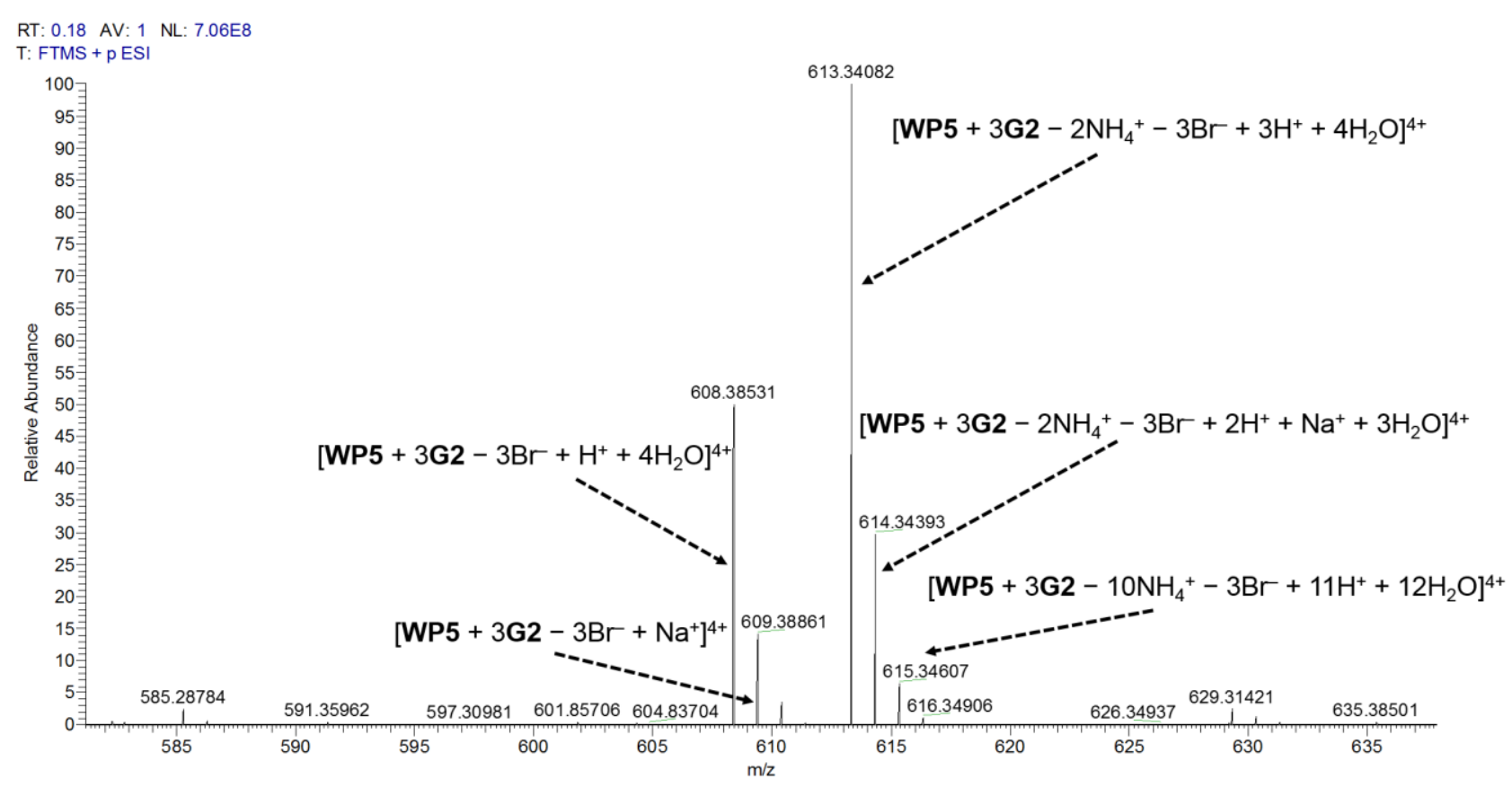

Figure S5 High-resolution mass electrospray ionization mass spectrum of WP5つ3G2.

8. Critical aggregation concentration (CAC) determination of $\mathbf{G 2 ,}, \mathbf{G} \mathbf{2}^{\prime}$ and $\mathbf{W P 5} 3 \mathbf{3 G 2}$
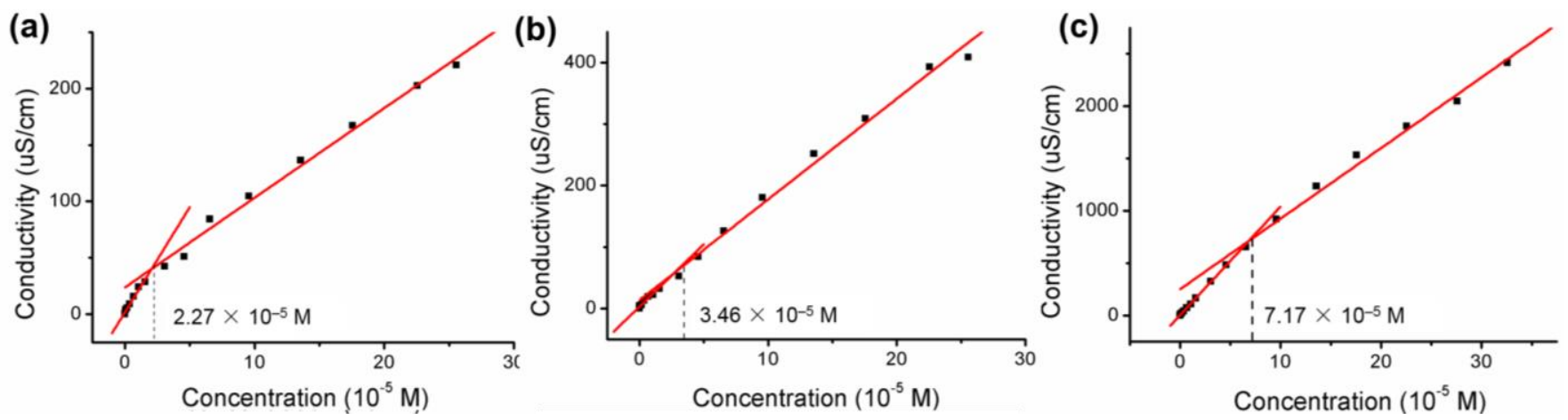

Figure S6 (a) The concentration-dependent conductivity of G2. The critical aggregation concentration (CAC) was determined to be $2.27 \times 10^{-5} \mathrm{M}$. (b) The concentration-dependent conductivity of G2'. The critical aggregation concentration (CAC) was determined to be $3.46 \times 10^{-5} \mathrm{M}$. (c) The concentration-dependent conductivity of WP5د3G2. The critical aggregation concentration (CAC) was determined to be $7.17 \times 10^{-5} \mathrm{M}$. 
9. DFT-optimized structure of $\mathbf{G} \mathbf{2}$ by Gaussian computer program

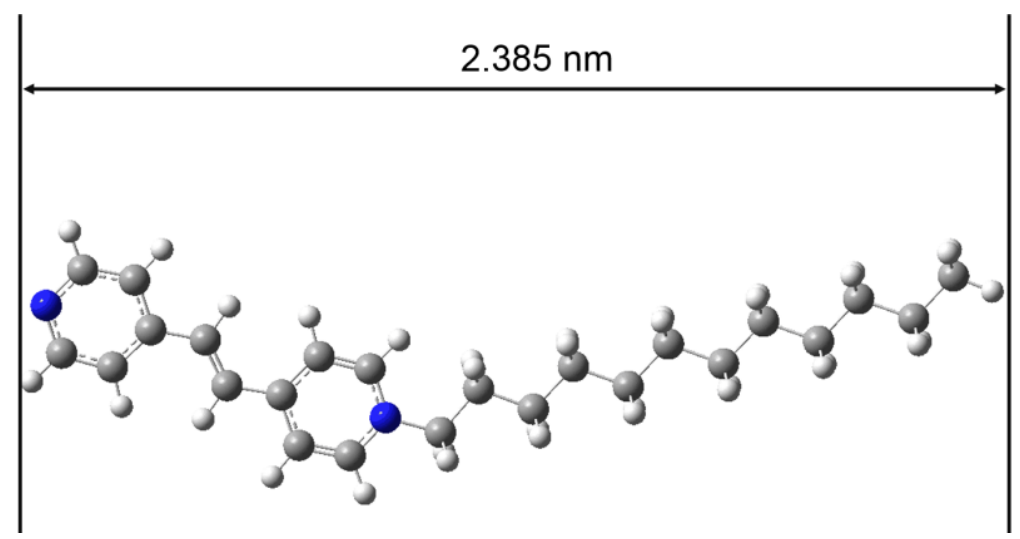

Figure S7 DFT-optimized structure of $\mathbf{G 1}$ by the Gaussian 09 program.

10. The theoretical extended length of WP5د3G2

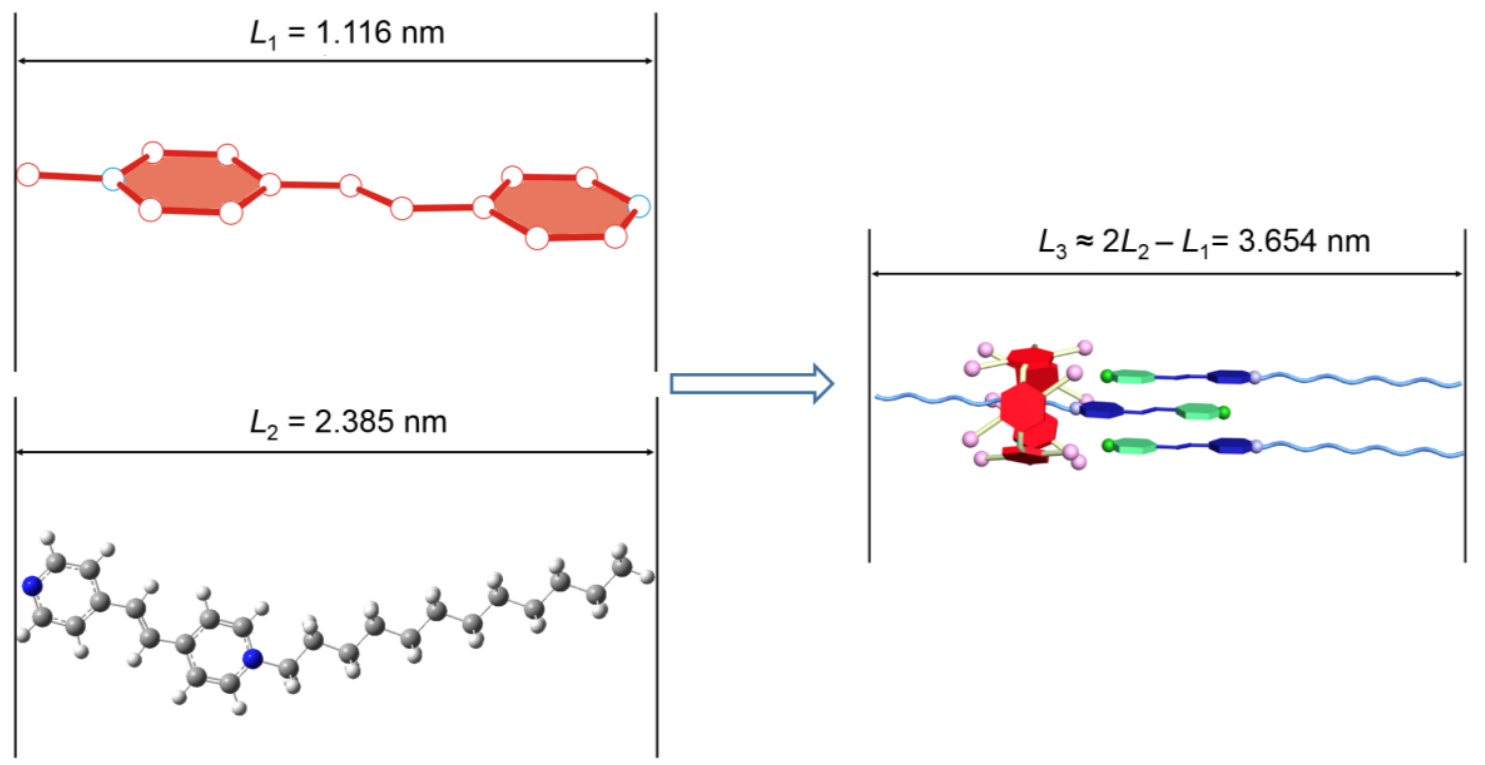

Figure S8 The theoretical extended length of WP5つ3G2. 
References:

S1. P. Wang, Y. Yao and M. Xue, Chem. Commun., 2014, 50, 5064-5067.

S2. B. J. Coe, S. P. Foxon, E. C. Harper, M. Helliwell, J. Raftery, C. A. Swanson, B. S. Brunschwig, K. Clays, E. Franz, Javier Garín, J. Orduna, P. N. Horton and M. B. Hursthouse, J. Am. Chem. Soc., 2010, 132, $1706-1723$.

S3. N. V. El'chishcheva, Yu. V. Shklyaev, Zh. A. Vnutskikh,1 T. F. Odegova, Yu. S. Chekryshkin and S. S. Dubrovina1, Pharm. Chem. J., 2010, 44, 251-253.

S4. Sheldrick, G. M. Acta Cryst., 2015, A71, 3.

S5. Sheldrick, G. M. Acta Cryst., 2008, A64, 112.

S6. M.J. Frisch, G.W. Trucks, H.B. Schlegel, G.E. Scuseria, M.A. Robb, J.R. Cheeseman, G. Scalmani, V. Barone, B. Mennucci, G.A. Petersson, H. Nakatsuji, M. Caricato, X. Li, H.P. Hratchian, A.F. Izmaylov, J. Bloino, G. Zheng, J.L. Sonnenberg, M. Hada, M. Ehara, K. Toyota, R. Fukuda, J. Hasegawa, M. Ishida, T. Nakajima, Y. Honda, O. Kitao, H. Nakai, T. Vreven, J.A. Montgomery, Jr., J.E. Peralta, F. Ogliaro, M. Bearpark, J.J. Heyd, E. Brothers, K.N. Kudin, V.N. Staroverov, R. Kobayashi, J. Normand, K. Raghavachari, A. Rendell, J.C. Burant, S.S. Iyengar, J. Tomasi, M. Cossi, N. Rega, J.M. Millam, M. Klene, J.E. Knox, J.B. Cross, V. Bakken, C. Adamo, J. Jaramillo, R. Gomperts, R.E. Stratmann, O. Yazyev, A.J. Austin, R. Cammi, C. Pomelli, J.W. Ochterski, R.L. Martin, K. Morokuma, V.G. Zakrzewski, G.A. Voth, P. Salvador, J.J. Dannenberg, S. Dapprich, A.D. Daniels, O. Farkas, J.B. Foresman, J.V. Ortiz, J. Cioslowski, and D.J. Fox, Gaussian 09W, revision A.02; Gaussian, Inc.: Wallingford, CT, 2009. 